\title{
Esthetic and functional restoration in a child with S-ECC using Contemporary and Biological Techniques
}

Rajesh Hemant Bariker ${ }^{1}$, Praveen Kumar Mandroli², Niraj Gokhale 3 , Pallavi Pujar ${ }^{4}$

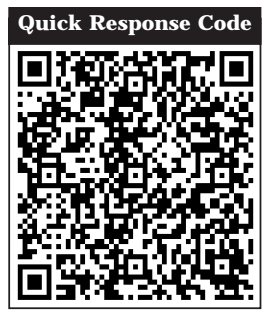

doi: $10.5866 / 2014.631649$

1Post Graduate Student

Dept of Pedodontics and Preventive Dentistry

Maratha Mandal's Nathajirao. G. Halgekar Institute of Dental Sciences, Near KSRP Ground, Bauxite Road, Belgaum-590 010, India

2Professor and HOD

${ }^{3 \&} 4$ Senior Lecturer

Dept of Pedodontics

Maratha Mandal's Nathajirao. G. Halgekar Institute of Dental Sciences, Near KSRP Ground, Bauxite Road, Belgaum-590 010, India

\section{Article Info:}

Received: April 13, 2014

Review Completed: May 12, 2014

Accepted: J une 10, 2014

Available Online: October, 2014 (www.nacd.in)

(C) NAD, 2014 - All rights reserved

Email for correspondence:

dr_rajesh@ive.com

\begin{abstract}
:
S-ECC describes dental caries in the primary dentition of young children that occur abruptly, spreading widely and rapidly and is burrowing in nature resulting in early involvement of the dental pulp. The case report presented here is of a 3.5 year old girl with severely decayed maxillary anterior teeth. After pulpectomy, the primary maxillary centrals were reinforced using polyethylene fiber-reinforced composite resin posts and restored using strip crowns and laterals biologically restored using tooth obtained from another patient. The combination of techniques described here offers a simple and effective method for restoring severely decayed primary anterior teeth that reestablishes function and esthetics.
\end{abstract}

Key words: Early Childhood Caries; Biologic Restoration; Fiber post

problem which exists in our most vulnerablecitizens - 'Our Children.' M ost frequent presentation of ECC is severely mutilated primary anterior teeth. Their loss at an early age may not only lead to establishment of neuro-muscular imbalanceleading to decreased masticatory efficacy but also phonetic
Dental caries is one of the most prevalent diseases of mankind. It has affected human race since times immemorial, especially during early childhood. As J onathan Kozol rightly said that ECC (Early Childhood Caries) is a grave public health

\section{Indian Journal of Dental Advancements}

Journal homepage: www. nacd. in 
and esthetic problems, development of parafunctional, psychological problems. To restore them is thus a challenge for the clinician. Diverse treatment options are available today like stainless steel crowns, cheng crowns, dura crowns, strip crowns, glastech crowns, pedojacket crowns etc. Out of the various treatment options available to rehabilitate severely destroyed tooth crowns, conservatively and biologically, several authors have suggested the use of tooth structure as a restorative material.1,2 Although dental caries has been declining globally in general population, its prevalence in children has not shown a significant decline. Restoring these is a challenging job for the pedodontist and over the years many clinicians have tried various procedures to restore them. In cases where teeth are severely decayed, endodontic treatment and placement of intracanal posts or retainers become necessary before crown restoration. ${ }^{3}$ Posts may be constructed of a variety of materials, including resin composite, metal, and biologic material. ${ }^{4}$ Restorative treatment options mentioned in the literature include direct and indirect techniques using prefabricated crowns, as well as biologic and resin composite restorations. ${ }^{1,2}$ Santos and Bianchi in 1991 coined the term "biological restoration" while the first paper reporting the use of fragments of extracted teeth as dental restorative materials was published in 1964 by Chosak and Eidelman. ${ }^{5}$ Ramires-Romito et al used teeth from the human tooth bank of Sao Paulo University Dental School to be used as natural posts and crowns to fit into the roots and replace the crowns as well. ${ }^{6}$

The present case report describes the case of a 3.5 year old girl with severely decayed maxillary anterior teeth that were restored using polyethylene fiber-reinforced composite resin posts and biologic restoration.

\section{CASE REPORT}

A 3.5 year old girl child reported to the Department of Pedodontics and Preventive Dentistry in Maratha Mandal's N.G.H Institute of Dental Sciences and Research Centre, Bel gaum with chi ef complaint of decayed teeth. The child's medical history was non-contributory. A detailed questioning of feeding habits revealed history of bottle feeding till the age of 3 years. Oral hygiene practices involved brushing once daily sometimes without toothpaste. The loss of coronal portion had affected the speech articulation of the child. Clinical and radiographic examinations were conducted and a diagnosis of "Severe early childhood caries" was established.

Examination revealed caries with $55,54,53,52$, $51,61,62,63,64,65,74,75,84$ and 85 (F igure 1). Root stumps seen with $51,52,61,62$; deep occlusal caries with 64. Proximal caries with 74 and 84 and grossly destructed 54, 75 and 85 were seen (F igure 2).

A comprehensive treatment plan was formulated after thorough clinical and radiologic examination.

\section{RADIOLOGIC INTERPRETATION}

Radiograph examination with 51, 52, 61, 62, 65, 75 and 85 confirmed pulpal involment and 54 and 85 showed gross destruction of crown

\section{TREATME NT}

Diet analysis, counselling and oral prophylaxis were undertaken in the first visit. In the upper arch, Root stumps with 51, 52, 61 and 62 were not mobile. Endodontic rehabilitation and aesthetic rehabilitation of the mutilated incisors were considered with pulpectomy, followed by polyethylene fibre reinforced composite resin posts and strip crowns with 51,52, 61, 62. Due to availability of natural crowns of the similar colour shade, biologic restoration was planned with 52 and 62. 53 and 63 presented with smooth surface caries and were indicated for Resin modified Glass ionomer cement. 54 was indicated for extraction, followed by a Band and loop space maintainer. 65 was indicated for pulpectomy, followed by stainless steel crown.

In lower arch, 85 was planned for extraction, followed by distal shoe space maintainer. 75 and 84 were indicated for pulpectomy, which were then restored with stainless steel crowns.

\section{TREATMENT PROGRESS}

The treatment was implemented in 2 phases for 51, 52, 61 and 62: Phase 1- Endodontic treatment and Phase 2- Aesthetic rehabilitation. Owing to the 


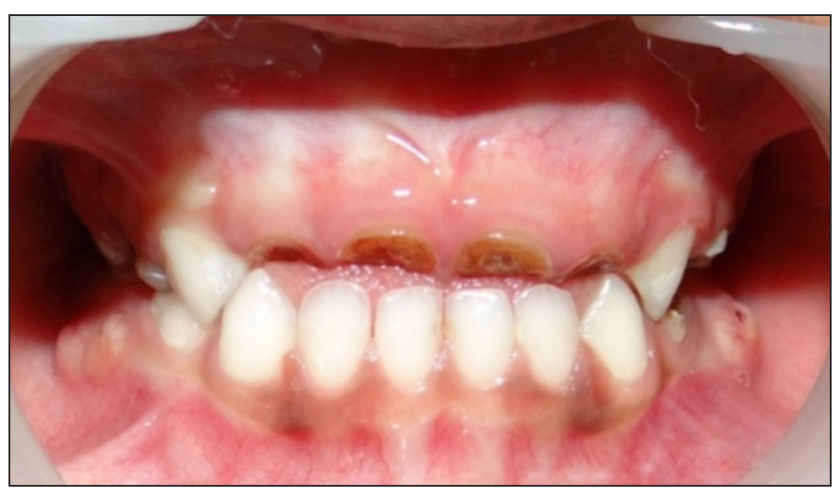

Figure 1: Intra oral photograph

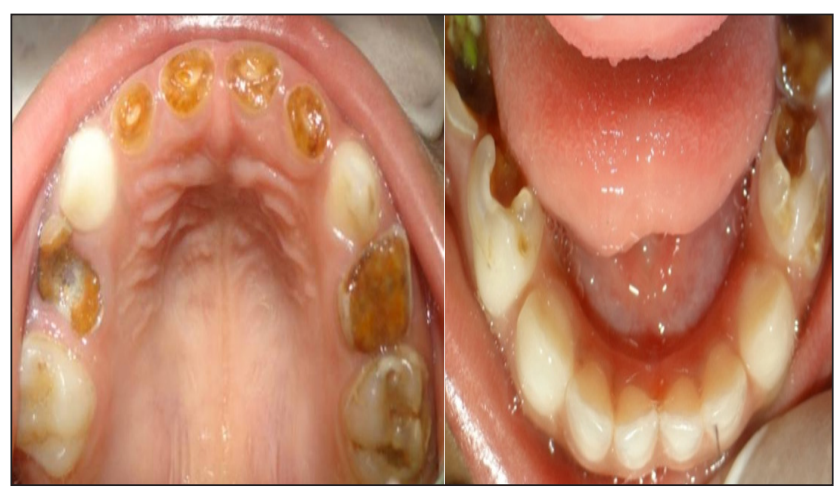

Figure 2: Upper arch and Lower arch showing decayed teeth

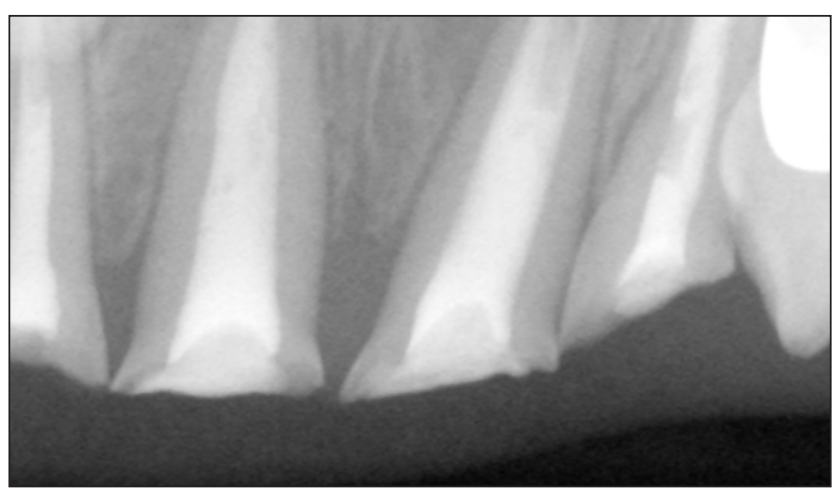

Figure 3: Radiograph after completing pulpectomy with 52,51,61,62

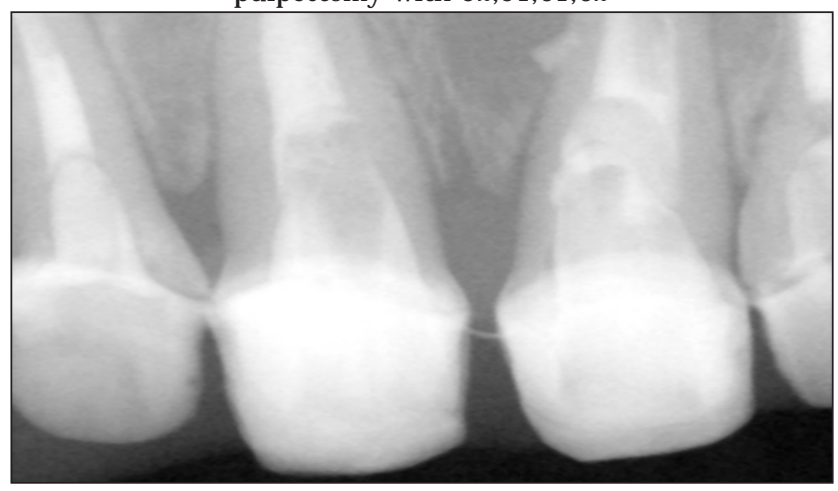

Figure 4: Post space created, polyethylene fiber post insertion and core build up done.

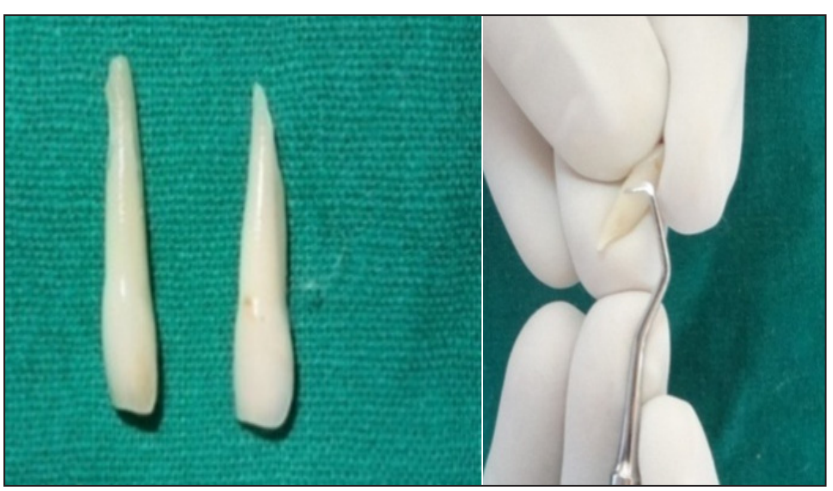

Figure 5: Freshly extracted teeth. Removal of soft tissue and PDL remnants from the root surface.

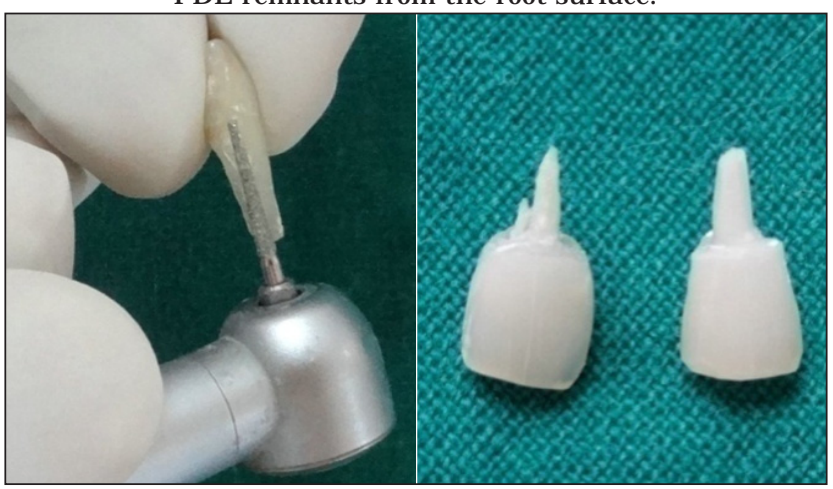

Figure 6: Preparation and Retrograde filling of root-stump with flowable composite Preparation.

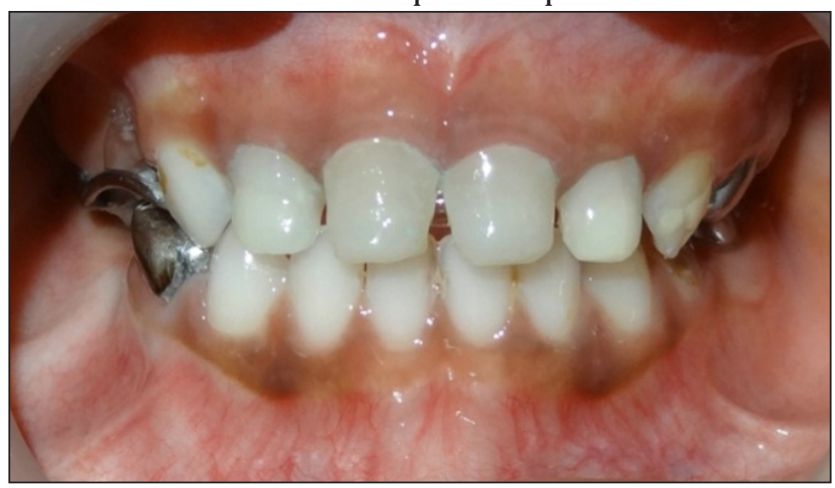

Figure 7: Final esthetic result

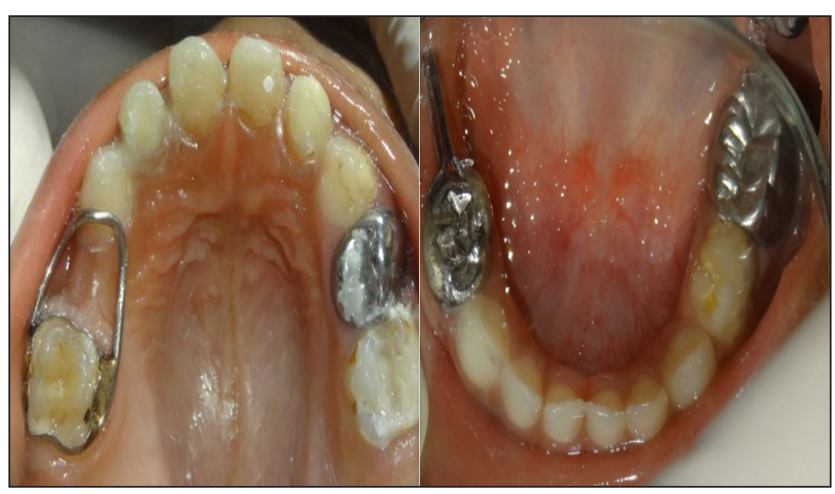

Figure 8: Band and L oop space maintainer with 55, S.S crown with 64; Distal shoe space maintainer with 85 and S.S crown with 75. 
patient's age, separate sessions were required for each restoration.

\section{Phase 1: Endo.tic treatment}

Gross carious lesions were removed with a no. 330 round carbide bur (S.S. White, N.J USA). Access to the pulp chamber was gained and working length determination IOPA was taken. After copious irrigation with $2.5 \% \mathrm{NaOCl}$ and Normal Saline, the root canal was dried using paper points. A thick mix of zinc-oxide eugenol paste was then condensed with spreader into the canal with incremental technique (Figure 3).

\section{Phase 2: Esthetic rehabilitation}

\section{A) Polyethylene fiber, followed by strip crowns.}

The post space was prepared in the second appointment, three days after the endodontic treatment was completed. The post space was created by removing approximately $4 \mathrm{~mm}$ of $\mathrm{ZnOE}$ material using a thin straight fissure bur with rubber stopper attached to a contra-angl e handpiece. The diameter of the straight bur used was less than the root canals. All visibleZnOE cement on the walls of the post space was removed. The post-space was air dried and a $1 \mathrm{~mm}$ base of glass ionomer cement (Fuji II, GIC Corp, Tokyo, J apan) was placed to isolate the obturated material from the rest of post space (Figure 4)

The prepared post space was then cleaned with saline, air-dried and acid etched with $37 \%$ phosphoric acid (Prime Dental, Thane, India) for 15 seconds. This space was rinsed and air dried with oil-free compressed air. A light cured bonding agent (3M ESPE ${ }^{\circledR}, M N$, USA) was brushed on the etched surface and uniformly dispersed by a compressed air blast. It was then light cured for 20 seconds.

The length of the fiber post was determined an polyethylene fiber post (Everstick, GC Corp, J apan) and was cured for 20 seconds in order to gain rigidity, before insertion into the post space. Light cured flowable composite resin ( $3{ }^{\circledR}{ }^{\circledR} \mathrm{ESPE}, \mathrm{MN}$, USA) was then inserted into the canal chamber and then the polyethylene post was inserted and cured for 60 seconds. The coronal portion of the glass fibre reinforced composite post was splayed to increase the surface area for the retention of the core.

The coronal enamel was then etched for 20 seconds, rinsed with water and air dried followed by application of bonding agent which was then light cured. The coronal post was covered with flowable composite for core build-up and light cured for 60 seconds.

An appropriate strip crown (3M ESPE ${ }^{\circledR}, \mathrm{MN}$ USA) was selected and trimmed to create an arched interproximal margin to accommodate the interdental papilla. The strip crown was filled with composite resin and placed on the tooth and cured for 60 seconds. The cured strip crown was peeled off with the help a sharp explorer and final finishing and polishing was done. Occlusal interferences in normal and paranormal mandibular movements were removed and postoperative radiographs were taken.

\section{B) Preparation of the biological restoration}

The obturating material with 52 and 62 in the coronal one third of the root was removed and root was prepared to receive intracanal portion of the biologic post and selected sterilized natural teeth were cleared of soft tissue and periodontal ligament remnants from the root surface (Figure 5 ), and their apical third was removed (Figure 6) and the remaining root stump filled with flowablecomposite material (Figure 7). The tooth was then tried for fit in the prepared root canal and readjusted for a snug fit. The finally prepared crown and root were cemented into the prepared root canals. Excess extruded material was finished and pol ished to give a final esthetic result (Figure 8).

\section{DISCUSSION}

Esthetic restoration of primary teeth has long been a special challenge to pediatric dentists. Loss of anterior teeth has a far-reaching impact on an individual's psyche and when it comes to children, it becomes all the more important. These days children are more aware of their surroundings and sometimes become very conscious about the loss of their deciduous teeth. In such patients, Restoration with a glass fiber post cemented with a flowable 
composite as it is an alternative treatment for restoring anterior primary teeth due to its retentive strength and mode of fracture. ${ }^{7}$ Conventional glass ionomer restorations have demonstrated high failure rates in the primary dentition. ${ }^{6}$ When there is severe loss of coronal tooth structure, the use of posts placed inside the canal after endodontic treatment will give retention, provide stability to the reconstructed crown, and withstand masticatory forces in function. ${ }^{8,9}$

In recent years, various types of fibre reinforcement have come into widespread use as an alternative to cast or prefabricated metal posts in the restoration of endodontically treated teeth. ${ }^{10} \mathrm{~A}$ number of studies have documented the clinical and laboratory success of polyethylene fiber and glass fiber posts in restoring primary teeth. ${ }^{11-19}$ The advantages of using polyethylene fibre to construct an intracanal post include resin composite crown reinforcement, translucency, and relative ease of manipulation. ${ }^{20}$

The reinforcement of composite resins by fibers improves both their fracture toughness and resistance. ${ }^{21}$ Polyethylene fibers are preferred as they improve the impact strength, modulus of elasticity, and flexural strength, and are almost invisible in the resinous matrix, in contrast to glass fibers, which fail to stick to the resinous matrix and carbon and Kevlar fibers, which interfere with the esthetics. ${ }^{22}$

In the past, the only treatment option for pulpally involved primary teeth would have been to extract the teeth and replace them with prosthetic substitutes, until the permanent teeth erupted. However, the availability of natural crowns and roots would allow the use of biologic restorations to preservethe integrity of patient's natural dentition, in the meantime provide excellent esthetic, functional advantages to achieve the morphofunctional restoration. This method of using biological crown and post restoration for primary teeth affected by ECC has shown promising results.

Also, this technique is simple, provides excellent esthetics, preserves natural tooth colour, allows the preservation of sound tooth structure and has low cost. ${ }^{23}$ The enamel of the biologically restored tooth has physiologic wear and offers superficial smoothness and cervical adaptation compatible with those of surrounding teeth. Biological restorations not only mimic the missing part of the oral structures, but are also bi ofunctional. ${ }^{24}$ Advantages include, the length of each appointment is reduced because natural teeth are prepared previously and clinical chair time for fragment bonding procedures is relatively short, which is a merit especially while dealing with paediatric patients. However, disadvantages of the biological restoration technique include the difficulty in obtaining teeth with the required coronal dimensions and characteristics, problems inherent to indirect restorations and matching fragment colour with tooth remnant colour. Also, having fragments from other people's teeth in their mouth is not a pleasant idea for some patients and many of them refuse to receive this treatment. However, all these factors are not contraindications of the technique. ${ }^{2}$

\section{OUTCOME AND FOLLOW UP}

The restorations were evaluated for any marginal discoloration, loss of restoration, color change, recurrent caries and retention after 3 months, 6 months and 1 year. The gingival health was visually and clinically inspected with explorer. The assessment of patient's response to treatment indicated positive change in behaviour, speech and self esteem.

\section{CONCLUSION}

Based on the positive results in the literature and our own clinical experience, it may be concluded that biological restoration as well as the fiber post has a practical clinical applicability and is a viable, esthetic restorative procedure for primary teeth with severely damaged crowns. This method of using biological and post restoration for restoring teeth affected by ECC has shown promising results when compared to the conventional method of using intracanal reinforced composite resin restorations. There was also improved psychological behavior and patient acceptance with this procedure. Hence we recommend the use of these techniques to rehabilitate the primary anterior teeth in cases of ECC in children. 


\section{REFERENCES}

1. Mandroli PS. Biologic restoration of primary anterior teeth: a case report. J Indian Soc Pedod Prev Dent 2003; 21:9597.

2. Mathur S, Chopra R, Pandit IK, Srivastava N, Gugnani N. Biological Restoration of a Grossly Decayed Deciduous Mandibular Molar. J CDR 2012; 6:139-141.

3. Croll TP. Bonded composite resin crowns for primary incisors: technique update. Quintessence Int 1990; 21:153157.

4. Grosso FC. Primary anterior strip crowns: a new technique for severely decayed anterior primary teeth. J Pedod 1987; 11:375-384.

5. Santos J, Bianchi J . Restoration of severely damaged teeth with resin bonding systems: case reports. Quintessence Int 1991; 22:611-615.

6. Ramires-Romito ACD, Wanderley MT, Oliveira MDM, I mparato J CP, Correa MSNP. Biologic restoration of primary anterior teeth. Quintessence Int 2000; 31:405-411.

7. Memarpour M,Shafiei, Abbazadeh $M$. Retentive strength of different intracanal posts in restoration of anterior primary teeth. Restor Dent Endodod 2013; 38;215-221.

8. Galassi MAP et al. Rehabilitacao de dentes deciduous anteriores: relato e acompanha-mento de um caso clinic. J Bras Odontoped Odont Bebe 1999; 2:175-178.

9. Vieira $\mathrm{Cl}$, Riberio CC. Polyethylene fiber tape used as a post and core in decayed primary anterior teeth. A treatment option. J Clin Pediatric Dent 2001; 26:1-4.

10. Qualtrough AJ , Mannocci F. Tooth-colored post systems: a review. Oper Dent 2003; 28:86-91.

11. Bayrak S, TuncES, Tuloglu N. Polyethylenefiberreinforced composite resin used as a short post in severely decayed primary anterior teeth: a case report. Oral Surg Oral Med Oral Pathol Oral Radiol Endod 2009; 107:60-64.

12. Memarpour M, Shafiei F. Restoration of primary anterior teeth using intracanal polyethylene fibers and composite: an in vivo study. J Adhes Dent 2013; 15:85-91.
13. Island G, White GE. Polyethylene ribbon fibers: a new alternative for restoring badly destroyed primary incisors. J Clin Pediatr Dent 2005; 29:151-156.

14. J ain M, Singla S, Bhushan B, Kumar S, Bhushan A. Esthetic rehabilitation of anterior primary teeth using polyethylene fiber with two different approaches.J Indian Soc Pedod Prev Dent 2011; 29:327-332.

15. Motisuki C, Santos-Pinto L, GiroEM. Restoration of severely decayed primary incisors using indirect composite resin restoration technique. Int J Paediatr Dent 2005;15:282-286.

16. Subramaniam P, Babu KL, Sunny R. Glass fiber reinforced composite resin as an intracanal post-a clinical study. J Clin Pediatr Dent 2008;3 2:207-210.

17. Metha D, Gulati A, Basappa N, Raju OS. Esthetic rehabilitation of severely decayed primary incisors using glass fiber reinforced composite: a case report. J Dent Child (Chic) 2012; 79:22-25.

18. Gujjar KR, Indushekar KR. Comparison of the retentive strength of 3 different posts in restoring badly broken primary maxillary incisors. J Dent Child (Chic) 2010; 77: 17-24.

19. Pithan S, Vieira RdeS, Chain MC. Tensile bond strength of intracanal posts in primary anterior teeth: an in vitro study. J Clin Pediatr Dent 2002; 27:35-39.

20. Rocha Rde O, das Neves LT, Marotti NR, Wanderley MT, Corrêa MS. Intracanal reinforcement fiber in paediatric dentistry:a case report. Quintessence Int 2004; 35:263-268.

21. Chafaie and R. Portier, "Anterior fiber-reinforced composite resin bridge: a case report," Pediatric Dentistry 2004; 26:530-534.

22. Vitale MC, Caprioglio C, Martignone A, Marchesi U, Botticelli AR. Combined technique with polyethylene fibers and composite resins in restoration of traumatized anterior teeth. DentTraumatol2004; 20:172-177.

23. Ehrmann EH. Restoration of a fractured incisor with exposed pulp using original tooth fragment: report of a case. J Am Dent Assoc 1989; 118:183.

24. Kapur A, Chawla HS, Goyal A, Gaube K. An esthetic point of view in very young children. J Clin Pediatr Dent 2005; 30:99-103.

\section{Gain quick access to our journal online View our journal at} www.nacd.in 